\title{
Manejo nutricional com micronutrientes e seus efeitos sobre os componentes de
}

\section{produtividade na cevada}

\author{
Nutritional management with micronutrients and their effects on yield components in barley \\ Manejo nutricional con micronutrientes y sus efectos sobre los componentes del rendimiento en \\ cebada
}

Recebido: 23/02/2021 | Revisado: 02/03/2021 | Aceito: 09/03/2021 | Publicado: 17/03/2021

\author{
Isabela Leticia Pessenti \\ ORCID: https://orcid.org/0000-0002-5176-3134 \\ Universidade Cesumar, Brasil \\ E-mail: isabelaleticiapessenti@gmail.com \\ Adalci Leite Torres \\ ORCID: https://orcid.org/0000-0001-9663-1007 \\ Universidade Cesumar, Brasil \\ E-mail: adalci.torres@unicesumar.edu.br \\ Warlyton Silva Martins \\ ORCID: https://orcid.org/ 0000-0002-7284-3395 \\ Universidade Estadual de Ponta Grossa, Brasil \\ E-mail: warlytonsilva@gmail.com \\ Nádia Macoski \\ ORCID: https://orcid.org/0000-0003-1109-7023 \\ Universidade Cesumar, Brasil \\ E-mail: nadiamacoski@gmail.com
}

\begin{abstract}
Resumo
$\mathrm{Na}$ cevada, a deficiência nutricional, ocasionada pelo déficit de micronutrientes, é um fator-chave que afeta negativamente a sua produtividade. Dentre os micronutrientes, o Zinco (Zn) e o Boro (B) estão sendo amplamente estudados em detrimento ao crescimento da planta, tal qual a qualidade do seu produto, os quais são favorecidos pelo suprimento balanceado desses micronutrientes. Nesta concepção, o presente trabalho objetivou avaliar a aplicação de zinco no tratamento de sementes e pleno perfilhamento e a aplicação de boro via adubação foliar, combinados ou não na cultura da cevada na Região dos Campos Gerais -PR. O delineamento foi em blocos casualizados com 4 níveis de tratamento e 4 repetições, cujas parcelas foram compostas por 5 linhas de cevada com 2 metros de comprimento e espaçadas por $0,45 \mathrm{~m}$, totalizando $4,5 \mathrm{~m}^{2}$. Os tratamentos foram: testemunha, $\mathrm{Zn}$ : aplicação de zinco $4 \mathrm{ml} \mathrm{kg}-1 \mathrm{via}$ tratamento de sementes e no estádio de pleno perfilhamento; B: aplicação foliar de boro no estádio R1; Zn + B: aplicação combinada de $\mathrm{Zn}$ e B. Foram avaliados o rendimento de grãos (com umidade corrigida para 13\%), componentes do rendimento (número de espiguetas por planta, número de grãos por planta, massa de grãos por planta e massa de mil grãos), estatura de plantas e a qualidade fisiológica de sementes. Os tratamentos de zinco e boro isolados aumentaram o rendimento de grãos e os componentes de rendimento para a cultivar BRS Cauê. Os parâmetros de qualidade fisiológica também foram superiores para os tratamentos de zinco e boro aplicados isoladamente. Apenas para o peso de mil sementes o zinco aumentou significativamente. Conclui-se que a aplicação de zinco via tratamento de sementes e pleno perfilhamento, assim como a aplicação foliar de boro proporcionam maiores rendimentos e melhoria na qualidade fisiológica das sementes de cevada.
\end{abstract}

Palavras-chave: Produtividade; Nutrição mineral; Micronutrientes.

\begin{abstract}
In barley, nutritional deficiency, caused by micronutrient deficit, is a key factor that negatively affects its productivity. Among the micronutrients, Zinc (Zn) and Boron (B) are being widely studied to the detriment of plant growth, such as the quality of their product, which are favored by the balanced supply of these micronutrients. In this conception, the present work aimed to evaluate the application of zinc in the treatment of seeds and full skinrs and the application of boron via foliar fertilization, combined or not in barley culture in the Campos Gerais Region -PR. The design was randomized with 4 treatment levels and 4 replicates, whose plots will consist of 5 barley lines with 2 meters long and spaced by $0.45 \mathrm{~m}$, totaling $4.5 \mathrm{~m}^{2}$. The treatments were: control, $\mathrm{Zn}$ : application of zinc $4 \mathrm{ml} \mathrm{kg-1}$ via seed treatment and at the stage of full planret; B: leaf application of boron in stage R1; $\mathrm{Zn}+\mathrm{B}$ : combined application of $\mathrm{Zn}$ and B. Grain yield (with corrected moisture for 13\%), yield components (number of spikelets per plant, number of grains per plant, grain mass per plant and mass of thousand grains), plant height and physiological quality of seeds were evaluated. The isolated zinc and boron treatments increased grain yield and yield components for cultivar BRS Cauê. The physiological quality parameters were also higher for the zinc and boron treatments applied alone. Only for the
\end{abstract}


weight of a thousand seeds zinc increased significantly. It was concluded that the application of zinc through seed treatment and full skinry, as well as the foliar application of boron provide higher yields and improvement in the physiological quality of barley seeds.

Keywords: Productivity; Mineral nutrition; Micronutrients.

\section{Resumen}

En la cebada, la deficiencia nutricional, causada por el déficit de micronutrientes, es un factor clave que afecta negativamente su productividad. Entre los micronutrientes, zinc (Zn) y boro (B) están siendo ampliamente estudiados en detrimento del crecimiento de la planta, como la calidad de su producto, que se ven favorecidos por el suministro equilibrado de estos micronutrientes. En esta concepción, el presente trabajo tenía como objetivo evaluar la aplicación del zinc en el tratamiento de semillas y skinrs completos y la aplicación de boro a través de la fertilización foliar, combinada o no en el cultivo de cebada en la Región Campos Gerais -PR. El diseño fue aleatorizado con 4 niveles de tratamiento y 4 réplicas, cuyas parcelas constarán de 5 líneas de cebada con 2 metros de largo y espaciadas por 0,45m, con un total de $4,5 \mathrm{~m}^{2}$. Los tratamientos fueron: control, $\mathrm{Zn}$ : aplicación de zinc $4 \mathrm{ml} \mathrm{kg}-1$ a través del tratamiento de semillas y en la etapa de planret completo; B: aplicación de hoja de boro en la etapa R1; Zn + B: aplicación combinada del rendimiento de Zn y B. Grain (con humedad corregida para 13\%), componentes de rendimiento (número de picos por planta, número de granos por planta, masa de grano por planta y masa de mil granos), altura de la planta y calidad fisiológica de las semillas fueron evaluados. Los tratamientos aislados de zinc y boro aumentaron el rendimiento de los granos y produjeron componentes para el cultivar BRS Cauê. Los parámetros de calidad fisiológica también fueron más altos para los tratamientos de zinc y boro aplicados solos. Sólo por el peso de mil semillas de zinc aumentó significativamente. Se concluyó que la aplicación del zinc a través del tratamiento de semillas y la piel completa, así como la aplicación foliar del boro proporcionan mayores rendimientos y mejora en la calidad fisiológica de las semillas de cebada.

Palabras clave: Productividad; Nutrición mineral; Micronutrientes.

\section{Introdução}

A cevada (Hordeum vulgare L.), no Brasil, é cultivada quase que exclusivamente para fins cervejeiros, sendo seu cultivo concentrado nos estados do Paraná, Rio Grande do Sul e Santa Catarina. Devido à grande demanda existente, principalmente da indústria malteira, a produção de grãos de cevada no país é insuficiente para suprir a demanda nacional desse grão, sendo esta suprida através de importação (Narwal et al., 2020).

Assim como as demais espécies cultivadas, a cevada necessita de apoio eficaz e contínuo da pesquisa. Por exemplo, na aplicação de novas tecnologias que busquem melhorar a expressão do potencial produtivo com o aumento da rentabilidade e da qualidade das sementes (Tavares et al., 2018). A área de cevada no Brasil tem se mantido em torno de 100 mil hectares nos últimos anos, em que o clima e os aspectos relacionados ao manejo nutricional definem o mapa de produção desta cultura, sendo a região Sul do Brasil onde se concentra a maior parte da produção (Narwal et al., 2020; Tavares et al., 2018).

No manejo nutricional, o zinco disponível na fase inicial de crescimento da cultura, principalmente no estádio vegetativo tem a função de estimular o desenvolvimento radicular. Na planta, quando o zinco aplicado via tratamento de sementes, a sua absorção pelas raízes é facilitada e mais rápida do que a absorção e translocação quando aplicado via foliar, conforme observado por Malavolta (2006) em plantas de trigo. Os autores observaram que durante o crescimento vegetativo, o zinco foi translocado principalmente para pontos de crescimento e folhas jovens. Enquanto que durante o crescimento reprodutivo, foi translocado principalmente para folhas no caule principal e para folhas acompanhadas de órgãos reprodutivos.

Sabe-se que cerca da metade das superfícies de cereais em crescimento em todo o mundo contêm baixos níveis de $\mathrm{Zn}$ disponível no solo, e plantas que crescem em áreas de deficiência de Zn apresentam baixos níveis de Zn no grão (Kaya, 2017). Uma alternativa para correção da deficiência de zinco é o tratamento de sementes, com base no princípio de que a reserva da semente é importante fonte de zinco para a prevenção do desenvolvimento de sintomas iniciais de deficiência na planta (Brunes et al., 2016).

Na planta, a atividade do zinco é efetiva para determinados processos na homeostase fisiológica e nutricional, atuando como ativador ou componente estrutural de enzimas, participante da fotossíntese nas plantas $\mathrm{C} 4$, através da enzima carboxilase pirúvica. É necessário para a produção de triptofano, aminoácido precursor do ácido indol acético, hormônio vegetal de 
crescimento envolvido no metabolismo do nitrogênio e necessário para manutenção da integridade das biomembranas (Malavolta, 2006).

Por outro lado, dentre os micronutrientes na nutrição de plantas, destaca-se o (B) por desempenhar diversas funcionalidades vitais, desde o transporte de açúcar, síntese e lignificações da parede celular, estrutura da parede celular, metabolismo de carboidratos, até o metabolismo de RNA. É um micronutriente de baixa mobilidade dentro do floema e, consequentemente, os sintomas de sua deficiência manifestam-se nos tecidos jovens ou recém-formados (Malavolta, 2006; Tombuloglu et al., 2016). Apesar de o papel fisiológico desse nutriente ainda não estar perfeitamente entendido, sabe-se da sua importância na formação da parede celular, mais especificamente na síntese de componentes, como a pectina, a celulose e a lignina, e no transporte de glicídios (Moraes et al., 2002).

Dessa forma, objetivou-se no presente estudo avaliar a eficiência da aplicação de micronutrientes sobre os componentes de rendimento na cultura da cevada na Região dos Campos Gerais - PR.

\section{Metodologia}

O experimento foi conduzido na área experimental do Centro Universitário de Maringá - Campus de Ponta GrossaParaná. De acordo com Koppen, a classificação climática do local é Cfb, subtropical úmido, com temperatura média nos meses mais frio e mais quente abaixo de $18^{\circ} \mathrm{C}$ e $22^{\circ} \mathrm{C}$, respectivamente, com ocorrência de geadas frequentes no inverno, verões frescos, e sem estação seca definida. A precipitação pluvial média anual é de $1.601 \mathrm{~mm}$, sendo o mês de agosto o mais seco e o de janeiro o mais chuvoso (Alvares et al., 2013).

O delineamento foi em blocos casualizados, com 4 tratamentos, sendo T1: testemunha (controle); T2: aplicação de zinco (Zn) 4ml kg-1 via tratamento de sementes e no estádio de pleno perfilhamento; T3: aplicação foliar de boro (B) (1L ha-1) no estádio R1; T4: aplicação combinada de Zn (4ml kg-1) no tratamento de sementes e B (1L ha-1) no estádio R1 (Zn+B), com 4 repetições cada. Foi utilizada a cultivar BRS Cauê.

A semeadura foi realizada na primeira quinzena de junho, empregando-se o sistema de semeadura direta, com adubação de base de N-P-K, conforme a recomendação da cultura para todos os tratamentos. Cada parcela foi composta por 5 linhas de cevada com 2 metros de comprimento, espaçadas por $0,17 \mathrm{~m}$, totalizando $4,5 \mathrm{~m}^{2}$. Os tratos culturais foram efetuados conforme recomendação para a cultura. Após atingir o ponto de maturidade fisiológica e umidade de $20 \%$, procedeu-se a colheita das unidades experimentais. Para determinação das variáveis de interesse agronômico, foram coletadas dez plantas aleatórias, representativas da área útil de cada unidade experimental. As variáveis qualitativas e quantitativas analisadas foram:

Altura da planta: Medida com auxílio de uma régua graduada, sendo a distância $(\mathrm{cm})$ entre nível do solo ao ápice das aristas das espigas. Os resultados foram expressos em centímetros.

Número de perfilhos por planta: Determinado a partir da contagem direta de todos os perfilhos. Resultados apresentados em unidades.

Número de espigas por metro quadrado: Determinou-se o número de espigas em 1,0 m², na área útil da parcela. Resultados expressos em unidades.

Número de sementes por planta: Determinado a partir da contagem direta do número de sementes presentes nas espigas da planta. Resultados demonstrados em unidades.

Peso de mil sementes: Determinado segundo as Regras de Análise de Sementes (BRASIL, 2009), a partir de oito repetições de 100 sementes, pesadas em balança de precisão. Os resultados foram expressos em gramas.

Rendimento de sementes: As plantas colhidas foram trilhadas e as sementes limpas, foram pesadas em balança de precisão, onde ajustou-se a umidade para 13\%, após ponderou-se o rendimento de sementes por hectare. Resultados expressos em kg ha-1 de sementes. 
Germinação: o teste de germinação foi conduzido em quatro unidades experimentais com quatro subamostras de 50 sementes, para cada tratamento. As sementes foram dispostas em papel germitest, embebido em água destilada na quantidade de 2,5 vezes a massa do substrato seco, visando o umedecimento adequado. Os rolos foram acondicionados em germinador com temperatura a $20^{\circ} \mathrm{C}$. As contagens foram realizadas no sétimo dia após a semeadura, os resultados expressos em percentagem de plântulas normais (Brasil, 2009).

Primeira contagem da germinação: realizada conjuntamente com o teste de germinação, avaliando-se a percentagem de plântulas normais, obtida por meio de quatro unidades experimentais com quatro subamostras de 50 sementes, para cada tratamento. A contagem foi realizada aos quatro dias após a semeadura. Os resultados expressos em percentagem de plântulas normais, metodologia proposta por Brasil (2009).

A normalidade dos dados foi testada pelo teste de Kolmogorov-Smirnov ao nível de 5\% de significância. Foi empregado a análise de variância (ANOVA) e as médias foram comparadas através do teste Scott-Knott, ao nível de 5\% de probabilidade. O software utilizado foi o R (R Core Team, 2020), utilizando o pacote ExpDes.pt.

\section{Resultados e Discussão}

Os dados de estatura de planta não foram significativos para os tratamentos aplicados ao teste de Scott-Knott a $5 \%$ de significância. Na Figura 1 e 2 observa-se que os tratamentos com aplicação de zinco (Zn) e boro (B) individualmente foram significativos, aumentando o rendimento de grãos e número de grãos por espigueta.

O tratamento de sementes com zinco tem como princípio, para sua eficiência, a translocação do zinco da semente para a planta, assim a reserva de zinco da semente passa a ser uma importante fonte de nutrição da planta (Ribeiro \& Santos, 1996; Tavares et al., 2018). Gonzalez et al. (2019) encontraram um aumento de $20 \%$ no rendimento de grãos com a dose de $5 \mathrm{~kg} \mathrm{ha}^{-1}$ quando comparado com a testemunha. Esse mesmo resultado foi observado neste trabalho com média de $12816 \mathrm{~kg} \mathrm{ha}^{-1}$ para o tratamento com aplicação de zinco.

Este efeito pode ser devido ao fato de que o $\mathrm{Zn}$ atua como um cofator para várias enzimas envolvidas no metabolismo de carboidratos, proteínas e auxinas, na integridade da membrana, e na floração e produção de sementes. Vários autores relataram aumento nos rendimentos de diferentes safras, como trigo, milho e arroz, com fertilização de zinco. Fornecer um suprimento adequado de $\mathrm{Zn}$ seria, portanto, parecer ser crucial para garantir que as lavouras utilizem insumos de fertilizantes eficientemente (Gonzalez et al., 2019; Narwal et al., 2020; Ribeiro \& Santos, 1996).

Segundo Tavares et al. (2018) quando o B é aplicado no perfilhamento, ocorre aumento no número de espiguetas e incremento no rendimento dos grãos quando a aplicação de B é realizada na semeadura. Neste trabalho os resultados foram positivos para rendimentos de grãos e números de espiguetas com a aplicação em estádio R1. 
Figura 1 - Rendimento de grãos (kg ha-1) da cevada BRS Cauê na safra 2020/2021. Testemunha (CONTROL); Zn: aplicação de zinco $4 \mathrm{ml} \mathrm{kg}^{-1}$ via tratamento de sementes e no estádio de pleno perfilhamento; B: aplicação foliar de boro no estádio R1; $\mathrm{Zn}+\mathrm{B}$ : aplicação combinada de Zn no tratamento de sementes e B no estádio R1. Médias seguidas de mesma letra não diferem entre si pelo teste de Scott Knott $(p \leq 0,05)$.

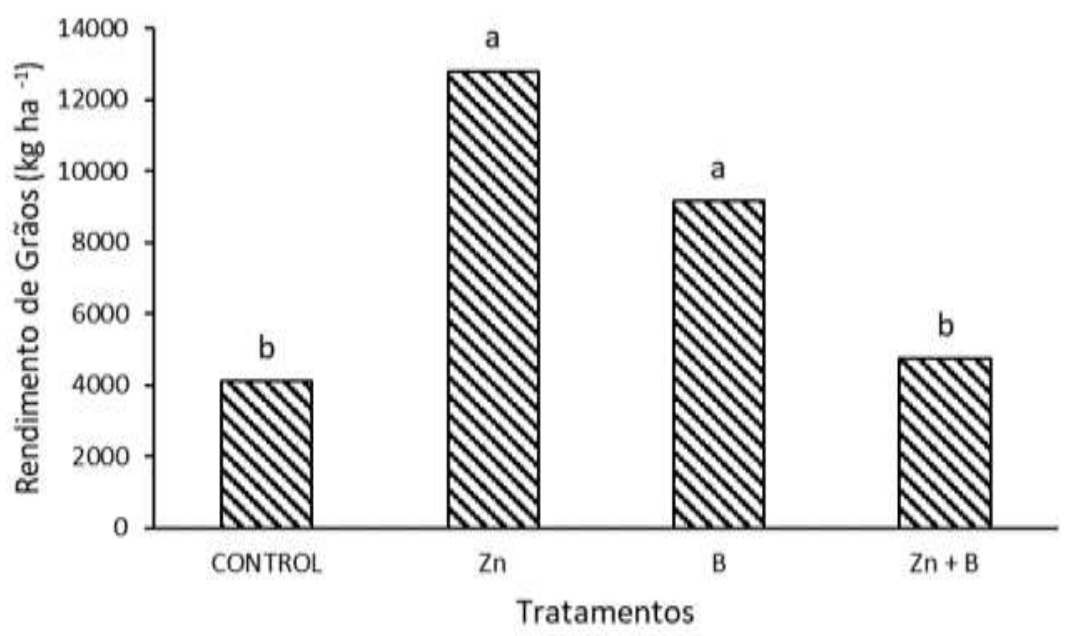

Fonte: Autores.

Figura 2 - Número de grãos por espigueta da cevada BRS Cauê na safra 2020/2021. Testemunha (CONTROL); Zn: aplicação de zinco $4 \mathrm{ml} \mathrm{kg}^{-1}$ via tratamento de sementes e no estádio de pleno perfilhamento; B: aplicação foliar de boro no estádio R1; $\mathrm{Zn}+\mathrm{B}$ : aplicação combinada de Zn no tratamento de sementes e B no estádio R1. Médias seguidas de mesma letra não diferem entre si pelo teste de Scott Knott $(\mathrm{p} \leq 0,05)$.

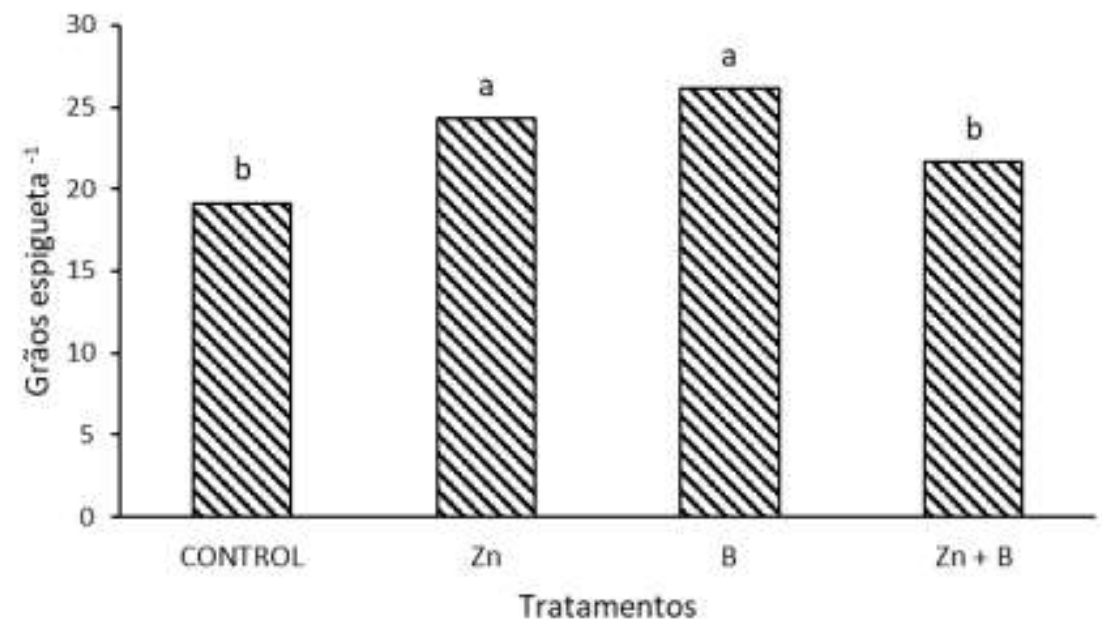

Fonte: Autores.

Na Figura 3, observa-se que o tratamento com aplicação de Zn e B aumentaram estatisticamente quando comparado com os demais tratamentos, para as variáveis número de espigueta por $\mathrm{m}^{2}$. 
Figura 3 - Número de espigueta por $\mathrm{m}^{2}$ da cevada BRS Cauê na safra 2020/2021. Testemunha (CONTROL); Zn: aplicação de zinco $4 \mathrm{ml} \mathrm{kg}^{-1}$ via tratamento de sementes e no estádio de pleno perfilhamento; B: aplicação foliar de boro no estádio R1; Zn + B: aplicação combinada de Zn no tratamento de sementes e B no estádio R1. Médias seguidas de mesma letra não diferem entre si pelo teste de Scott Knott $(\mathrm{p} \leq 0,05)$.

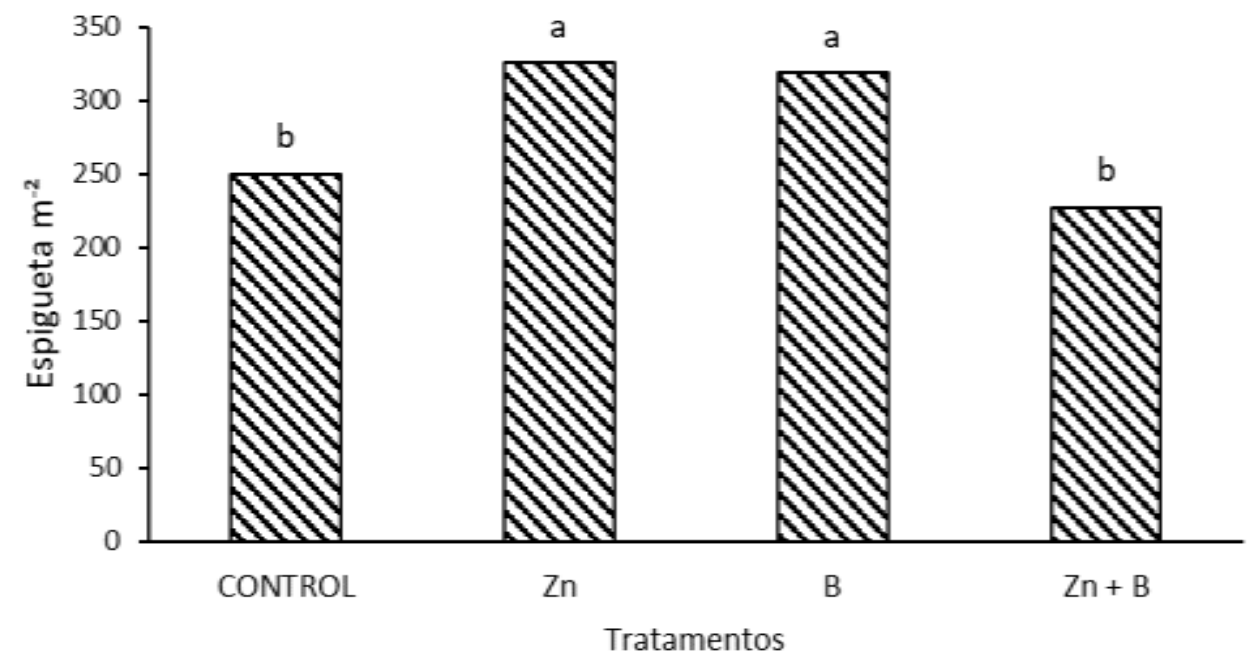

Fonte: Autores.

Para as variáveis agronômicas, número de espigueta por planta (Figura 4) e peso de mil sementes (Figura 5), o tratamento com zinco aumentou estatisticamente em relação aos demais, já para os tratamentos testemunha, aplicação individual de B, e a combinação de Zn + B não foram significativas. Gonzalez et al. (2019) observaram que os tratamentos 10 e $15 \mathrm{~kg} \mathrm{ha}^{-1} \mathrm{de} \mathrm{Z}$ aumentaram a concentração de zinco 2,5 vezes nas folhas, caule e grão em relação a testemunha na cv. Quench, na Espanha.

Figura 4 - Número de espigueta por planta da cevada BRS Cauê na safra 2020/2021. Testemunha (CONTROL); Zn: aplicação de zinco $4 \mathrm{ml} \mathrm{kg}^{-1}$ via tratamento de sementes e no estádio de pleno perfilhamento; B: aplicação foliar de boro no estádio R1; $\mathrm{Zn}+\mathrm{B}$ : aplicação combinada de Zn no tratamento de sementes e B no estádio R1. Médias seguidas de mesma letra não diferem entre si pelo teste de Scott Knott $(p \leq 0,05)$.

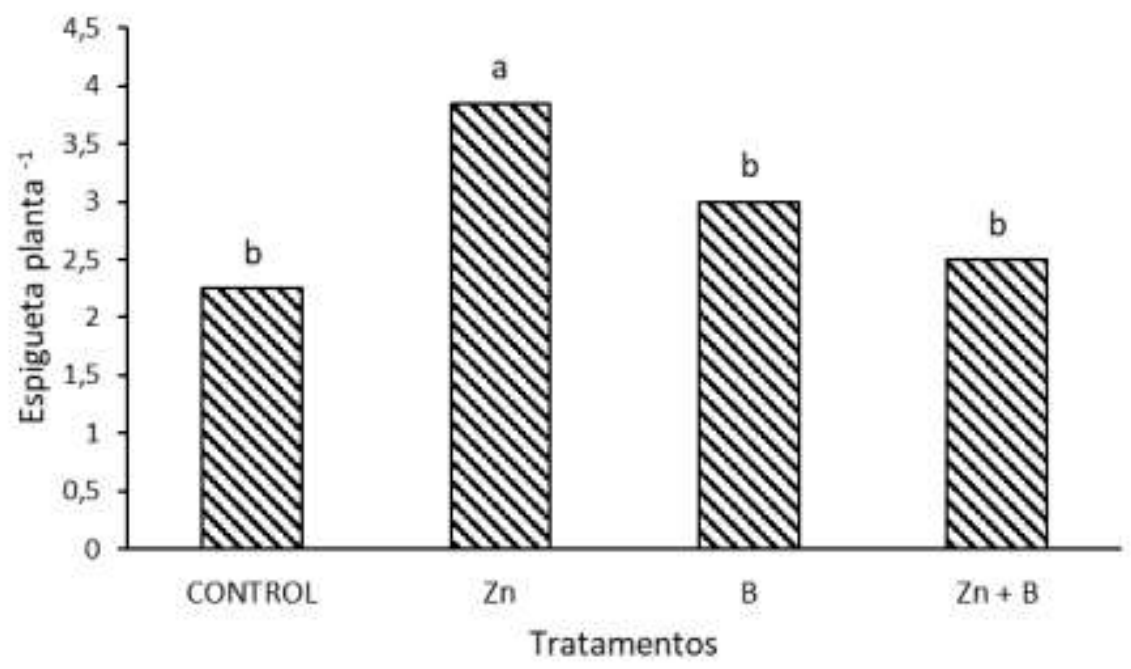

Fonte: Autores. 
Figura 5 - Peso de mil sementes (PMS) (g) da cevada BRS Cauê na safra 2020/2021. Testemunha (CONTROL); Zn: aplicação de zinco $4 \mathrm{ml} \mathrm{kg}^{-1}$ via tratamento de sementes e no estádio de pleno perfilhamento; B: aplicação foliar de boro no estádio R1; Zn + B: aplicação combinada de Zn no tratamento de sementes e B no estádio R1. Médias seguidas de mesma letra não diferem entre si pelo teste de Scott $\operatorname{Knott}(\mathrm{p} \leq 0,05)$.

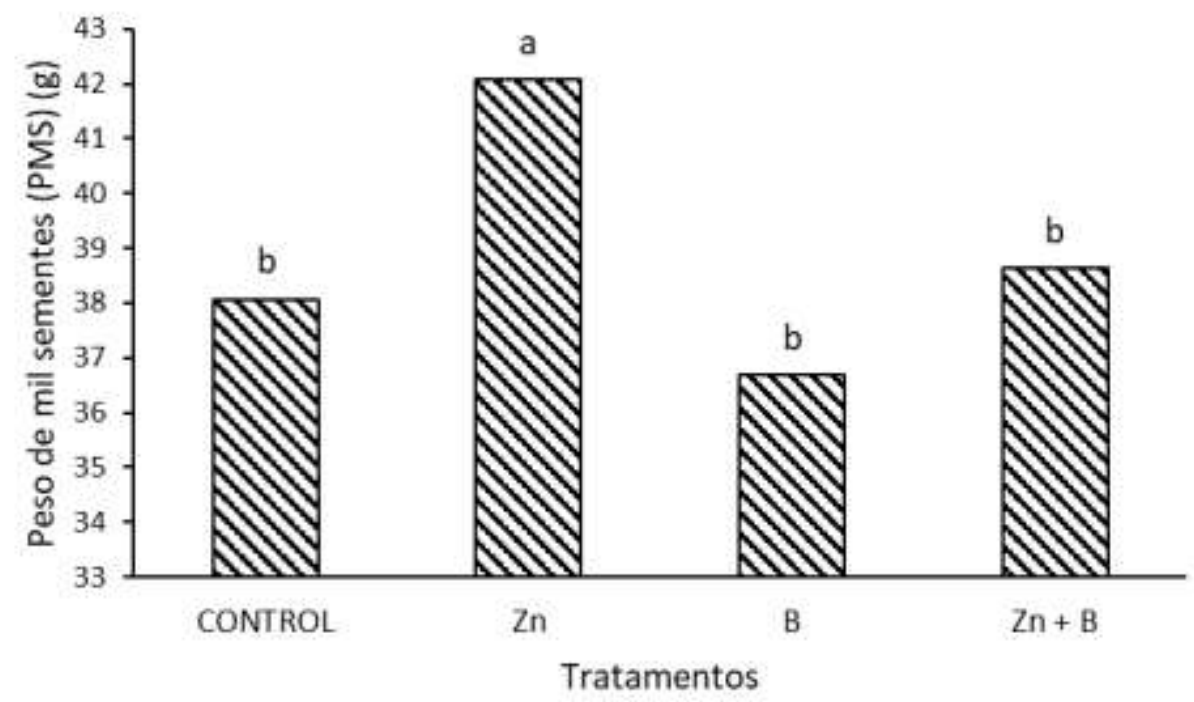

Fonte: Autores.

O zinco é um micronutriente essencial, presente na flora e na fauna (Roohani et al., 2013), e é radialmente absorvido pelas raízes e transportado como um cátion divalente por vias simplásticas e apoplásticas (Gupta et al., 2016) e atua como um componente estrutural e um cofator para muitas enzimas importantes, como superóxido dismutase, álcool desidrogenase e RNA polimerase (Castillo-González et al., 2018). Também está envolvido no alívio de diferentes processos físico-bioquímicos em plantas, como taxa fotossintética (Ashraf et al., 2020), formação de pólen (Pandey et al., 2006), metabolismo de carboidratos e proteínas, absorção de nutrientes (Weisany et al., 2014) e qualidade da semente (Ebrahimian et al., 2017).

Segundo Tavares et al. (2018) existe uma relação entre o suprimento de boro e a capacidade de produção e viabilidade do pólen. Além disso, o boro estimula a germinação, particularmente o desenvolvimento do tubo polínico. Neste trabalho, o tratamento com B no estádio R1 apresentou maior quantidade de grãos por espigueta, porém houve menor peso de mil sementes. Alguns autores encontraram resposta linear para o peso de mil sementes, tendo o aumento das doses de boro até $5 \mathrm{~kg}$ ha-1, tanto na semeadura como perfilhamento (Tavares et al., 2018).

O boro é um elemento de baixa mobilidade dentro do floema e, consequentemente, os sintomas de sua deficiência manifestam-se nos tecidos jovens ou recém-formados (Malavolta, 2006). Apesar de o papel fisiológico desse nutriente ainda não estar perfeitamente entendido, sabe-se da sua importância na formação da parede celular, mais especificamente na síntese de componentes, como a pectina, a celulose e a lignina, e no transporte de glicídios (Moraes et al., 2002). Os requisitos de B nas partes reprodutivas da planta são maiores do que nas partes vegetativas da planta. O maior requisito de B dos tecidos reprodutivos pode explicar por que o crescimento reprodutivo é particularmente sensível à limitação de $\mathrm{B}$ e o fato de que reduções no rendimento de sementes foram relatadas sem quaisquer outros sintomas durante o crescimento vegetativo (Matthes et al., 2020).

O boro desempenha, também, importante papel na migração e no metabolismo de carboidratos, facilitando o transporte dos açúcares através das membranas celulares na forma do complexo açúcar-borato (Malavolta, 1997). Para o 
aumento do potencial produtivo dos cultivos, a decisão de aplicação ou não de boro é vital, pois esse elemento é exigido em pequenas quantidades e o intervalo de deficiência e toxicidade é estreito, exigindo-se cautela para que haja o fornecimento de doses adequadas (Kaya, 2017), uma vez que a toxicidade pode ser constatada mesmo com baixos níveis no solo. Dessa forma, práticas de manejo e de adubação, detectando a dose e a época adequada de aplicação de boro, podem ser fundamentais para o aumento da sua eficiência e da produtividade de sementes da cultura (Archana \& Verma, 2017; Matthes et al., 2020).

No milho, a deficiência de B influencia negativamente a produtividade, mas, em comparação com outros cereais, foi relatado que o milho tem uma exigência de B relativamente baixa para a produtividade máxima. Quando cultivado sob deficiência de B, ao entrar na fase reprodutiva, as folhas superiores exibem estrias translúcidas e as plantas produzem orelhas múltiplas (inflorescência feminina no milho), que podem abrigar uma estrutura semelhante a uma borla (inflorescência masculina no milho), com poucas sedas curtas (estigmas das orelhas do milho) (Matthes et al., 2020).

Para os parâmetros fisiológicos avaliados, o teste de germinação foi significativo para os tratamentos de Zn e B aplicados separadamente. A testemunha e a combinação dos dois nutrientes não foram significativas (Figura 6).

Figura 6 - Teste de germinação (\%) da cevada BRS Cauê na safra 2020/2021. Testemunha (CONTROL); Zn: aplicação de zinco $4 \mathrm{ml} \mathrm{kg}^{-1}$ via tratamento de sementes e no estádio de pleno perfilhamento; B: aplicação foliar de boro no estádio R1; Zn + B: aplicação combinada de Zn no tratamento de sementes e B no estádio R1. Médias seguidas de mesma letra não diferem entre si pelo teste de Scott Knott $(\mathrm{p} \leq 0,05)$.

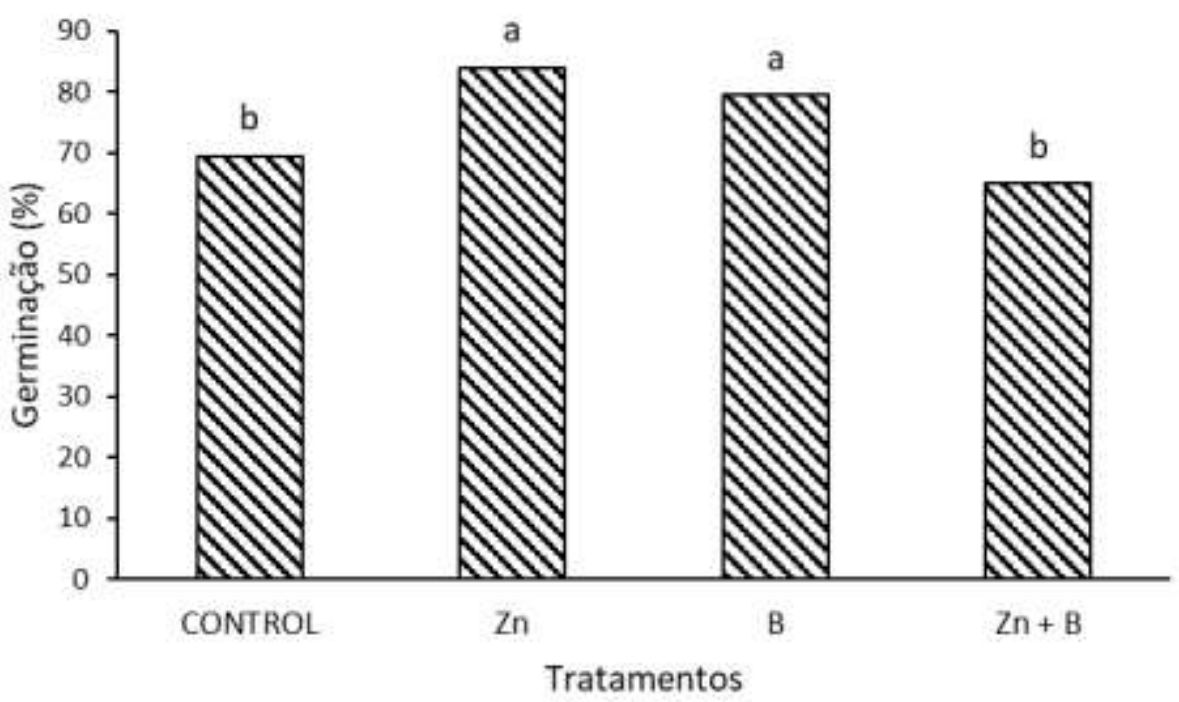

Fonte: Autores.

Tavares et al. (2018) observaram que a porcentagem de plântulas normais, verificada pelo teste de primeira contagem de germinação, foi reduzida linearmente para cada $\mathrm{kg} \mathrm{ha}^{-1}$ de boro para aplicação na semeadura e no perfilhamento, respectivamente. Indicando que o boro não influenciou nos parâmetros fisiológicos. O mesmo foi verificado neste trabalho, exceto para o teste de germinação.

O tratamento das sementes (TS) com zinco objetiva aumentar o teor contido na semente, porém sua eficiência está relacionada com os efeitos que podem causar na germinação e no vigor das sementes e na resposta das culturas. As sementes tratadas com zinco podem apresentar melhorias na germinação e no vigor, quando enriquecidas com zinco. O TS com zinco, varia com a dose, nem sempre é suficiente para satisfazer a necessidade total da planta, mas sua maior disponibilidade inicial estimula o desenvolvimento do sistema radicular, aumentando a área de contato das raízes com o solo, proporcionando melhor 
desenvolvimento da planta (Narwal et al., 2020; Ribeiro \& Santos, 1996).

Os micronutrientes são elementos químicos essenciais para o crescimento das plantas, exigidos em quantidades reduzidas. O Zn tem papel funcional nos principais mecanismos celulares, como fotossíntese, integridade da membrana, síntese de proteínas, metabolismo de carboidratos e fertilidade. $\mathrm{O} \mathrm{Zn}$ tem uma forte tendência para formar complexos tetraédricos com ligantes de nitrogênio, oxigênio e enxofre e desempenha papéis catalíticos e estruturais em reações enzimáticas. A carência de zinco reflete-se no crescimento e na produção das plantas, nas quais ele desempenha importantes funções. Segundo Ribeiro e Santos (1996) podem ser observados sintomas de deficiência como clorose acentuada ao longo na nervura principal, encurtamento dos entrenós e menor produção de folhas novas, podendo aparecer tonalidades roxas no caule e nas folhas, além de redução no crescimento e na produção de grãos.

Desta maneira, a avaliação da dose e a época adequada para o manejo e adubação de boro podem ser fundamentais para o aumento da sua eficiência e da qualidade de sementes da cultura. Uma das formas de avaliar as deficiências dos nutrientes, que podem causar prejuízos na produção e na qualidade das sementes, pode ser feita através da avaliação de alterações que podem ocorrem em determinados sistemas enzimáticos.

Durante o crescimento inicial das plântulas, o suprimento de zinco pode ser feito de duas maneiras: translocação da reserva da semente e absorção pelas raízes. Sob condições de temperatura e intensidade luminosa baixas, o zinco da semente se constitui na principal fonte durante o crescimento inicial das plântulas. O suprimento do zinco da semente torna-se importante fonte para as plantas, especialmente no início do desenvolvimento, quando as condições de ambiente são tais que restringem o crescimento radicular e/ou quando a concentração de zinco no substrato é baixa.

Nos últimos anos, o progresso na pesquisa B foi feito na identificação e caracterização de mutantes com transporte B prejudicado, compreensão dos mecanismos subjacentes de homeostase e regulação B, desenvolvimento de técnicas de imagem B, e estudar as possíveis interações de B com fitohormônios. Além disso, as mudanças mediadas por B nas relações da planta com a água e as implicações nas interações de B com outros fatores abióticos, como a seca, estão ganhando interesse na comunidade de pesquisa B (Matthes et al., 2020).

O boro não é constituinte de nenhuma enzima nem afeta diretamente qualquer atividade enzimática, mas tem um papel importante no transporte de açúcar, síntese da parede celular, lignificação da estrutura da parede celular, integridade da membrana, metabolismo de carboidratos, metabolismo de RNA, IAA e metabolismo de fenol. O boro também é provavelmente mais importante do que quaisquer outros micronutrientes para a produção de culturas de alta qualidade. As variedades tolerantes são uma das principais abordagens de obtenção de safras melhoradas em solos com estresse de boro (Archana \& Verma, 2017).

\section{Conclusão}

Os tratamentos com zinco e boro isolados aumentaram os componentes de rendimento e fatores agronômicos, assim como aumentou a qualidade fisiológica das sementes produzidas. O zinco aumentou o peso de mil sementes.

A combinação do zinco e boro não interferiu sobre os componentes de rendimento da cevada e a aplicação conjunta desses dois micronutrientes não foram efetivas.

\section{Referências}

Alvares, C. A., Stape, J. L., Sentelhas, P. C., de Moraes Gonçalves, J. L., \& Sparovek, G. (2013). Köppen's climate classification map for Brazil. Meteorologische Zeitschrift, 22(6), 711-728. https://doi.org/10.1127/0941-2948/2013/0507.

Archana, N. P., \& Verma, P. (2017). Boron deficiency and toxicity and their tolerance in plants: A review. J Global Biosci, 6, 4958-4965. 
Ashraf, M. Y., Tariq, S., Saleem, M., Khan, M. A., Hassan, S. W. U., \& Sadef, Y. (2020). Calcium and zinc mediated growth and physio-biochemical changes in mungbean grown under saline conditions. Journal of Plant Nutrition, 43(4), 512-525.

Brasil. (2009). Regras para análise de sementes.

Brunes, A. P., Mendonça, A. O., Oliveira, S. de, Lemes, E. S., Leitzke, I. D., \& Villela, F. A. (2016). Produção, qualidade e expressão isoenzimática de semente de trigo produzidas sob diferentes doses de boro. Revista Brasileira de Biociências, 14(3), Article 3. http://www.ufrgs.br/seerbio/ojs/index.php/rbb/article/view/3182.

Castillo-González, J., Ojeda-Barrios, D., Hernández-Rodríguez, A., González-Franco, A. C., Robles-Hernández, L., \& López-Ochoa, G. R. (2018). Zinc metalloenzymes in plants. Interciencia, 43(4), 242-248.

Ebrahimian, E., Bybordi, A., \& Seyyedi, S. M. (2017). How nitrogen and zinc levels affect seed yield, quality, and nutrient uptake of canola irrigated with saline and ultra-saline water. Communications in Soil Science and Plant Analysis, 48(3), 345-355.

Gonzalez, D., Almendros, P., Obrador, A., \& Alvarez, J. M. (2019). Zinc application in conjunction with urea as a fertilization strategy for improving both nitrogen use efficiency and the zinc biofortification of barley. Journal of the Science of Food and Agriculture, 99(9), 4445-4451. https://doi.org/10.1002/jsfa.9681.

Gupta, N., Ram, H., \& Kumar, B. (2016). Mechanism of Zinc absorption in plants: Uptake, transport, translocation and accumulation. Reviews in Environmental Science and Bio/Technology, 15(1), 89-109.

Kaya, E. (2017). Zinc efficiency and diversity of Montana wheat and barley (p. 1-130) [Thesis, Montana State University - Bozeman, College of Agriculture]. https://scholarworks.montana.edu/xmlui/handle/1/15328.

Malavolta, Eurípedes. (2006). Manual de nutrição mineral de plantas. Agronômica Ceres.

Malavolta, Eurípides. (1997). Avaliação do estado nutricional das plantas: Princípios e aplicações/Eurípedes Malavolta, Godofredo Cesar Vitti, Sebastião Alberto de Oliveira. (2a ed.), ver. E atual. Piracicaba: Potafos.

Matthes, M. S., Robil, J. M., \& McSteen, P. (2020). From element to development: The power of the essential micronutrient boron to shape morphological processes in plants. Journal of Experimental Botany, 71(5), 1681-1693. https://doi.org/10.1093/jxb/eraa042.

Moraes, L. A. C., Moraes, V. H. de F., \& Moreira, A. (2002). Relação entre a flexibilidade do caule de seringueira e a carência de boro. Pesquisa Agropecuária Brasileira, 37(10), 1431-1436.

Narwal, S., Kumar, D., Kharub, A. S., \& Verma, R. P. S. (2020). 11 - Barley biofortification: Present status and future prospects. In O. P. Gupta, V. Pandey, S. Narwal, P. Sharma, S. Ram, \& G. P. Singh (Orgs.), Wheat and Barley Grain Biofortification (p. 275-294). Woodhead Publishing. https://doi.org/10.1016/B978-0-12-818444-8.00011-0.

Pandey, N., Pathak, G. C., \& Sharma, C. P. (2006). Zinc is critically required for pollen function and fertilisation in lentil. Journal of Trace Elements in Medicine and Biology, 20(2), 89-96.

R Core Team. (2020). R: A Language and Environment for Statistical Computing. R Foundation for Statistical Computing. https://www.R-project.org/.

Ribeiro, N. D., \& Santos, O. S. dos. (1996). Aproveitamento do zinco aplicado na semente na nutrição da planta. Ciência Rural, 26(1), 159-165. https://doi.org/10.1590/S0103-84781996000100030.

Roohani, N., Hurrell, R., Kelishadi, R., \& Schulin, R. (2013). Zinc and its importance for human health: An integrative review. Journal of research in medical sciences: the official journal of Isfahan University of Medical Sciences, 18(2), 144.

Tavares, L. C., Lemes, E. S., Brunes, A. P., Oliveira, S. de, Mendonça, A. O. de, \& Villela, F. A. (2018). Suplementação de boro na semeadura e no perfilhamento em cevada: Amazonian Journal of Agricultural and Environmental Sciences, 61. https://periodicos.ufra.edu.br/index.php/ajaes/article/view/2648.

Tombuloglu, H., Ozcan, I., Tombuloglu, G., Sakcali, S., \& Unver, T. (2016). Aquaporins in Boron-Tolerant Barley: Identification, Characterization, and Expression Analysis. Plant Molecular Biology Reporter, 34(2), 374-386. https://doi.org/10.1007/s11105-015-0930-6.

Weisany, W., Sohrabi, Y., Heidari, G., Siosemardeh, A., \& Badakhshan, H. (2014). Effects of zinc application on growth, absorption and distribution of mineral nutrients under salinity stress in soybean (Glycine max L.). Journal of Plant Nutrition, 37(14), 2255-2269. 